\title{
Variable-frequency drives for electric irrigation pumping plants save energy
}

\author{
Blaine R. Hanson $\square$ Claus Weigand $\square \quad$ Steve Orloff
}

\begin{abstract}
The constant rpm (revolutions per minute) of electric motors prevents adjusting pump performance to match variable operating conditions, and therefore the pump output is usually reduced or throttled. Variable-frequency drives of electric motors have the potential to adjust pump performance to match operating conditions by reducing motor and pump rpm. Field tests at five sites showed that pump performance at the reduced rpm could reasonably match that under the throttled conditions, but at a much lower horsepower demand. However, for economic reasons, pumping plants using a variable-frequency drive should be operated at least 1,000 hours per year.
\end{abstract}

Pumps for irrigation should be selected to provide a design flow rate or capacity and total head at maximum pump efficiency. The actual operating conditions, however, can vary throughout the irrigation season, causing the pump to operate under conditions other than the design condition. For example, a single pump may be used to irrigate fields of different sizes, thus requiring the pump capacity to be decreased or throttled when irrigating the smaller fields. Pump performance may also change when irrigating irregularly shaped fields, which requires reducing either lateral lengths or the number of laterals per irrigation set.

Electric motors used for irrigation pumping plants normally operate at a constant number of revolutions per minute ( $\mathrm{rpm})$, preventing the irrigator from adjusting the pump performance to match the operating conditions. Variable- or adjustable-frequency drives for electric motors allow the pump rpm to be changed by varying the frequency of the power into the motor. A variable-frequency drive first converts the $A C$ power to $D C$ power and then changes the $\mathrm{DC}$ power into adjustable-frequency $A C$ power. As the frequency decreases the rpm of the motor is reduced, along with the horsepower demand of the pump. Pump capacity and total head are also reduced.

As shown in figure 1, a small change in rpm results in a large change in pump horsepower demand. This figure, developed using equations relating horsepower demand, total head and pump capacity to rpm, shows that reducing the rpm by $20 \%$ reduces the horsepower demand by

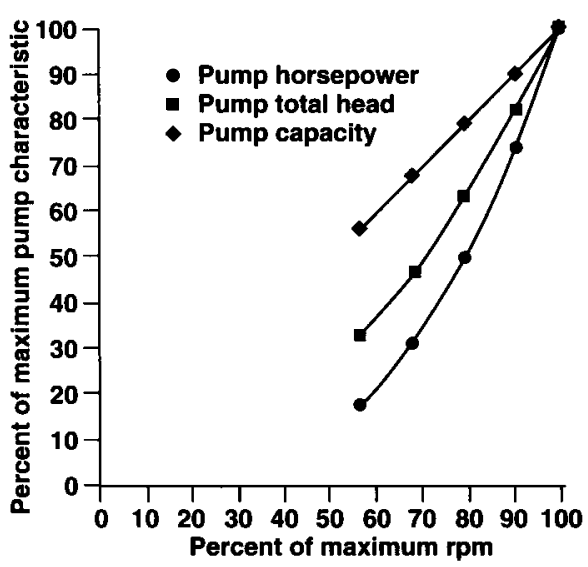

Fig. 1. Pump characteristics versus pump rpm.
$50 \%$. Thus, reducing the rpm from 1,770 to 1,400 decreases the horsepower demand of a 100-horsepower pump to 50 horsepower.

The pump capacity and total head also depend on the rpm (fig. 1). A $20 \%$ reduction in pump rpm reduces the pump capacity by $20 \%$ and reduces the total head by about $38 \%$.

The relationships in figure 1 are general descriptions of the effect of rpm changes on pump output. The actual total head and capacity at a particular rpm depends on the impeller design. Adjusting the pump rpm may not produce exactly the total head and capacity obtained under the throttledcapacity conditions.

Little information has been reported on using variable-frequency drives with irrigation pumping plants. Therefore the objective of this study was to evaluate the effect of reducing the rpm with a variable-frequency drive, on the pump output compared

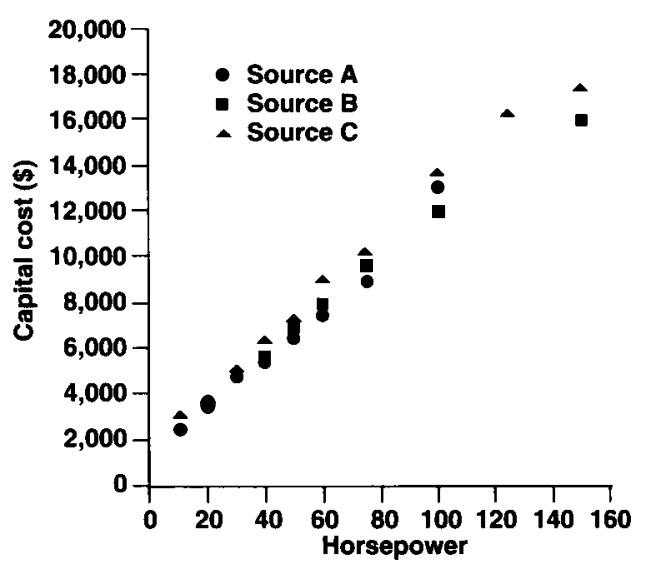

Fig. 2. Capital costs of variable frequency drives. 
to the desired output and on electricity costs.

\section{Pump tests at five sites}

We selected five field sites for this study. A variable-frequency drive mounted inside a van was transported from site to site. A pump test was first conducted under the operating condition normally used by the irrigator and then retested under the reduced rpm. Discharge pressure, pumping lift (where applicable), input horsepower and frequency of the power were measured for each test.

Site 1. Different blocks of tree crops were irrigated with a single centrifugal pump. Water was supplied from a reservoir. The pump was first tested while irrigating an 80-acre block, then tested on a 50-acre block that required reducing or throttling the pump capacity. A third test was conducted using the variable-speed drive to reproduce the output of the throttled pump by decreasing the rpm.

Results showed that the variable speed operation $(1,345 \mathrm{rpm})$ reasonably reproduced the output of the throttled operation $(1,770 \mathrm{rpm})$ (table 1). Pressure differences between the two operating conditions were small; however, the variable rpm operation produced $100 \mathrm{gpm}$ more. Input horsepower demand decreased $39 \%$, from 90 horsepower under the throttled condition to 55 horsepower at the reduced rpm. The pumping plant efficiency of the reduced rpm operation was nearly the same as that of the unthrottled operation.

Site 2. A deep-well turbine pump supplied water to both border-irrigated and sprinkler-irrigated fields. The pump discharged into a low-head pipe distribution system. A centrifugal pump was used to pressurize the sprinkler system. The deep-well turbine pump capacity was adequate for the border irrigation systems, but was excessive for the sprinkler system. The excessive capacity was discharged onto the border-irrigated fields during the sprinkler irrigation.

The variable-speed drive reduced the output of the deep-well turbine to match that needed by the sprinkler irrigation system by decreasing the pump rpm from 1,770 to 1,400 . The horsepower of the turbine pump was reduced from 132 to 68 , a $48 \%$ reduction. The pump capacity was decreased from $2,048 \mathrm{gpm}$ to $1,085 \mathrm{gpm}$. The overall pumping plant efficiency $(68 \%)$ was not changed by using the variable-frequency drive.

Site 3. An unthrottled centrifugal pump boosted the pressure for sprinkler-irrigated fields when canal water was available. When only well water was used, the discharge of the centrifugal pump was reduced to match the capacity of the deep-well turbine. The variable-frequency drive was used to reduce the capacity of the centrifugal pump to match that of the deep-well turbine.

The output of the centrifugal pump with the variable-frequency drive matched that of the throttled pump when the rpm was reduced from 1,770 to 1,400 . This resulted in a horsepower reduction of about $44 \%$, from 66 horsepower to 37 . Discharge pressure and pump capacity under the reduced rpm operation were $38 \mathrm{psi}$ and $670 \mathrm{gpm}$, and were $37 \mathrm{psi}$ and $720 \mathrm{gpm}$ under the throttled condition.

Site 4. A deep-well turbine and a centrifugal pump supplied water and pressure to a wheel-line sprinkler system. The sprinkler system was operated at times using three laterals, which required a pump discharge pressure of about 60 psi. At other times only two laterals were used, resulting in a discharge pressure of about 90 psi. The discharge of the pumping plant was not reduced under this condition. The excessive pressure caused overirrigation because irrigation set times were not adjusted for the higher sprinkler pressure.

The rpm of the centrifugal pump was decreased to reduce the discharge pressure to about 60 psi when only two laterals were operating. Results showed a horsepower reduction of the centrifugal pump from 45 to 20 , a $56 \%$ reduction. The rpm was reduced from 1,770 to 1,240 . The combined pumping plant efficiency of both pumps decreased from 51 to $44 \%$.

Site 5. A deep-well turbine pump supplied water to several center-pivot sprinkler systems. Sometimes the

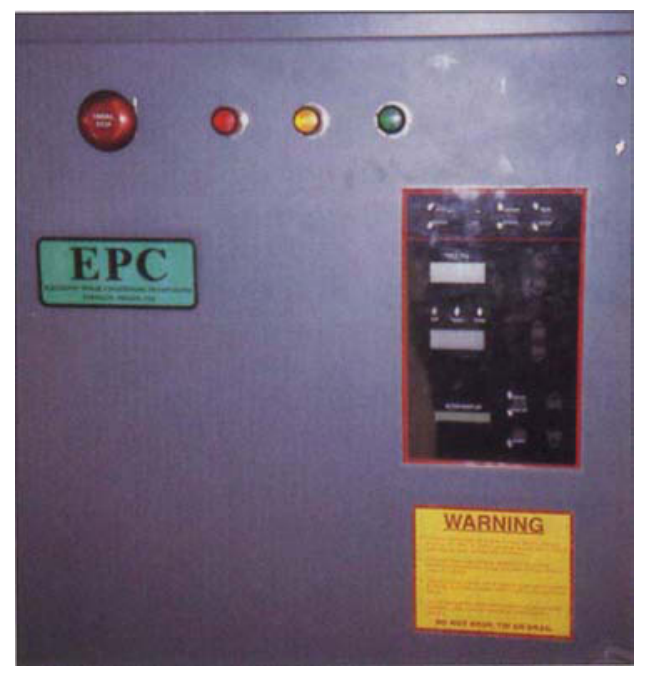

Prototype variable-frequency drive used for project.

pump was used to irrigate only one center-pivot machine, which resulted in a lateral inlet pressure of about 60 psi, compared to about 35 psi under normal operating conditions. Flow regulators on each sprinkler drop tube reduced the pressure to 24 to 26 psi.

The pressure at the center pivot was reduced down to about 35 psi using the variable-frequency drive. The rpm was decreased from 1,770 to 1,500 , which reduced the input horsepower from 90 to 61 , a $32 \%$ reduction. The pump capacity decreased from 815 gpm under the normal condition to $791 \mathrm{gpm}$ under the reduced rpm condition. The pumping plant efficiency changed from $54 \%$ to $57 \%$ under the reduced rpm.

\section{Economic considerations}

These results indicate that the pump output at the reduced rpm can reasonably match the desired output. The desired output occurred when the rpm was reduced from 1,770 to between 1,240 and 1,500, with three sites at about 1,400 rpm. Most horsepower reductions were between 25 and 35 ex-

\begin{tabular}{|c|c|c|c|}
\hline \multicolumn{4}{|c|}{ TABLE 1. Pump test results, Site 1} \\
\hline \multicolumn{2}{|c|}{ Unthrottled } & \multirow{2}{*}{$\begin{array}{c}\text { Throttled } \\
50\end{array}$} & \multirow{2}{*}{$\begin{array}{c}\begin{array}{c}\text { Variable } \\
\text { speed }\end{array} \\
50\end{array}$} \\
\hline Acres & 80 & & \\
\hline Pressure (psi) & 80 & 64 & 60 \\
\hline Pump capacity (gpm) & 1,100 & 600 & 700 \\
\hline Input horsepower & 128 & 90 & 55 \\
\hline RPM & 1,770 & 1,770 & 1,345 \\
\hline Overall efficiency $(\%)$ & 40 & 24 & 44 \\
\hline
\end{tabular}


cept for Site 2, which was reduced by 64 horsepower. With one exception, little change was found in the overall pumping plant efficiency.

Are variable-frequency drives economical? They can save energy by reducing the horsepower demand of irrigation pumps. The annual energy saving is the difference in energy cost between the constant rpm operation and the reduced rpm operation. This difference depends on the amount of decrease in horsepower, the operating time at the reduced rpm and the electricity costs.

\section{Payback period}

Figure 2 shows capital costs of variable-frequency drives using data from three sources. Costs ranged from about $\$ 2,500$ for a 10 -horsepower drive to more than $\$ 16,000$ for a 150 horsepower drive. Costs increased linearly with increasing horsepower.

These site observations were used to evaluate the economics of variablefrequency drives. First, the payback period was calculated for each site, an approach frequently used by irrigators. The payback period is the capital cost divided by the annual saving in energy costs. The payback method provides a rough estimate of the time required for an investment to pay for itself. Disadvantages of the payback

\begin{tabular}{|c|c|c|c|c|}
\hline \multicolumn{5}{|c|}{$\begin{array}{l}\text { TABLE 3. Annual net returns for the } \\
\text { case studies }\end{array}$} \\
\hline & \multicolumn{4}{|c|}{ Annual hours of operation } \\
\hline & 500 & 1,000 & 1,500 & 2,000 \\
\hline & \multicolumn{4}{|c|}{ 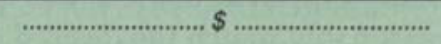 } \\
\hline Site 1 & -568 & 1,182 & 2,932 & 4,682 \\
\hline Site 2 & 454 & 3,654 & 6,854 & 10,054 \\
\hline Site 3 & -246 & 1,203 & 2,653 & 4,103 \\
\hline Site 4 & -149 & 1,101 & 2,351 & 3,601 \\
\hline Site 5 & -868 & 581 & 2,032 & 3,482 \\
\hline
\end{tabular}

method are that it fails to recognize savings that occur beyond the payback period and that it does not consider the time value of money.

A second approach calculated the net returns of using a variable-frequency drive by determining annual benefits and annual costs. The annual benefit is the annual saving in electricity costs. The annual cost is the annualized capital/installation cost of the variable-frequency drive, which depends on the initial capital/installation costs, the interest rate of return, and the economic life of the drive. The annualized cost for this study was based on an interest rate of $5 \%$ and an economic life of 10 years for the variable-frequency drive, based on industry recommendations. The annual net return is the annual benefit minus the annual cost.

Table 2 shows the payback period in years calculated for several different annual hours of operation. Large payback periods, nearly equal to the economic life of the drive, occurred for 500 hours of operation per year, except for Site 2, which had a large horsepower reduction. At 1,000 hours per year, the payback periods were considerably reduced, to between 4 and 6 years. Payback periods between 2 and 4 years generally occurred for 1,500 hours of operation.

Annual net returns, shown in table 3 , were either small or negative at 500 hours per year. A negative return occurs when the annual cost of the drive exceeds the annual benefit. Annual returns were much higher for operating times exceeding 1,000 hours per year. The smaller returns for Site 5 compared to Sites 3 and 4, which had similar horsepower reductions, reflect the

\begin{tabular}{|c|c|c|c|c|c|c|}
\hline & \multirow{2}{*}{$\begin{array}{l}\text { Horsepower } \\
\text { reduction }\end{array}$} & \multirow[b]{2}{*}{ Cost" } & \multicolumn{4}{|c|}{ Annual hours of operation } \\
\hline & & & 500 & 1,000 & 1,500 & 2,000 \\
\hline & & $\$$ & \multicolumn{4}{|c|}{ 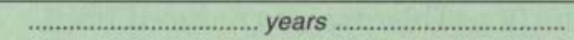 } \\
\hline Site 1 & 35 & 17,900 & 10.2 & 5.1 & 3.4 & 2.6 \\
\hline Site 2 & 64 & 21,200 & 6.6 & 3.3 & 2.2 & 1.6 \\
\hline Site 3 & 29 & 13,100 & 9.0 & 4.5 & 3.0 & 2.2 \\
\hline Site 4 & 25 & 10,800 & 8.6 & 4.3 & 2.9 & 2.2 \\
\hline Site 5 & 29 & 17,900 & 12.3 & 6.2 & 4.1 & 3.1 \\
\hline
\end{tabular}

larger horsepower demand of Site 5. The larger net returns for Site 2 reflect the relatively large horsepower reduction.

\section{Other concerns}

The adjustable $A C$ power generated from $D C$ power may contain distortions not found in $\mathrm{AC}$ power, which may increase motor temperature. An increase in heating may shorten the life of an electric motor. A report, "Adjustable Speed Drives: Application Guide," by the Electric Power Research Institute indicates that harmonics due to distorted current may increase motor heating by 3 to $15 \%$. The report states, however, that recent designs of variable-speed drives have been found to produce less than $5 \%$ heating, and that medium-voltage variable-speed drives were found not to cause any additional heating. The report suggests that additional heating by low-voltage drives should not be a problem if the motor service factor is 1.15 .

The variable-frequency drive can affect the efficiency of the irrigation pumping plant, since both motor efficiency and efficiency of the drive decrease with decreasing rpm. The EPRI study showed that the efficiency of the drive decreased slightly to about $50 \%$ of the maximum rpm, but at lower rpms the drive efficiency decreased substantially.

Variable-frequency drives must be protected from adverse environmental conditions. Good temperature control is necessary for prolonged life of the variable-frequency controller. One manufacturer recommends maintaining the ambient air temperature between $14^{\circ}$ and $122^{\circ} \mathrm{F}$, maintaining the humidity below $90 \%$ and operating the unit at an altitude below 3,300 feet. Field experience suggests that the temperature should be controlled during the summer using fans or air conditioners. Variable-frequency controllers should be operated in an atmosphere free of corrosive gas and dust. Wetting of the controller must also be prevented. A space heater is recommended to prevent condensation during winter fog. 


\section{Summary}

Variable-frequency drives offer the potential of adjusting the output of an irrigation pump to match variable operating conditions at a reduced energy cost. These field evaluations showed that the output of the pump could reasonably match the desired output by reducing the frequency and thus the pump rpm. These reductions were obtained by reducing the pump rpm from 1,770 to about 1,400 for most of these sites.

Horsepower reductions ranged from 32 to $56 \%$ of the initial horsepower. Four of the case studies had reductions greater than $39 \%$. These percentage reductions reflect the reduction in energy costs that occur if the operating hours at the reduced rpm are the same as the operating hours under the mismatched but constant rpm condition.

The economic analysis suggests that the pump should be operated at the reduced rpm for at least 1,000 hours per year to ensure a positive annual net return. The greatest potential for energy savings and positive annual net returns occurs for high electric energy rates, large horsepower reductions and long operating hours at the reduced horsepower demand.

B.R. Hanson is Irrigation and Drainage Specialist, UC Davis; C. Weigand is Engineer, Electronic Power Conditioning, Inc., Corvallis, Oregon; and S. Orloff is Farm Advisor, Siskiyou County.

We wish to acknowledge the funding provided by the California Energy Commission. We appreciate the cooperation of the growers who allowed us to test their pumping plants. We also wish to acknowledge the information provided by Matt Kehoe, Central Pump, Modesto; Cris Hepburn, McCalla Water Well Services, Redlands; Al Thompson, Eaton Corporation/Cutler-Hammer Products, Sacramento; Electric Motor and Supply, Fresno; and Cathy Calloway, Campbell and George Co., San Carlos. We express appreciation to the Electric Power Research Institute, Pleasant Hill, for providing the EPRI reports Adjustable Speed Drives: Directory (1991) and Adjustable Speed Guides: Applications Guides (1992).
1995 INDEX

Following are articles and sidebars (SB) appearing in California Agriculture, Volume 49, Numbers 1 through 6, January through December 1995. Back issues may be purchased, while supplies last, at $\$ 2.00$ per copy ( $\$ 3.00$ per copy for the Biodiversity Special Issue). Please make checks payable to UC Regents.

\section{ECONOMICS, FARM MANAGEMENT}

Can retailers depress lettuce prices at farm level? - Sexton, Zhang Mar-Apr p. 14

Crop and farm diversification provide social benefits - Johnston et al.

Jan-Feb p. 10

Coalition promotes sustainable practices - Campbell Jan-Feb p. 15 (SB)

Farm labor contractors play new roles in agriculture - Thilmany, Martin Sep-Oct p. 37

High piece-rate wages do not reduce hours worked - Billikopf Jan-Feb p. 17

How California agricultural producers manage risk - Blank, McDonald Mar-Apr p. 9

How new crop disaster policy could affect California - Lee, Harwood, Somwaru May-Jun p. 7

If medfly infestation triggered a trade embargo ... Embargo on California produce would cause revenue, job loss - Siebert, Cooper Jul-Aug p. 7

Optimizing tomato distribution to processors lifts profits little - Durham, Sexton, Song Sep-Oct p. 21

\section{ENVIRONMENT}

Efforts to reduce stratospheric ozone loss affect agriculture - Weare May-Jun p. 24

Special report: Biological diversity: What is it and why do we care?

Biodiversity indicators in California: taking nature's temperature - Soulé Nov-Dec p. 40

Setting priorities for conserving endangered species - Ralls (SB) p. 43

Can we stop farmland losses? Population growth threatens agriculture, open space - Medvitz, Sokolow Nov-Dec p. 11

Mono Lake compromise: A model for conflict resolution - Elliott-Fisk p.15 (SB)
Conjunctive use of farmland adds value ... Winter flooding of ricelands provides waterfowl habitat -

Brouder, Hill Nov-Dec p. 58

Residual rice seed is critical food for waterfowl - Miller, Wylie p. 61 (SB)

Waterfowl and rice in California's Central Valley - Reid, Heitmeyer p. 62 (SB)

Displaced by agriculture, urban growth . . . California wildlife faces uncertain future - Kucera, Barrett Nov-Dec p. 23

Economic incentives for growers can benefit biological diversity - Howitt Nov-Dec p. 28

Growers respond to contamination ... Changes in pest control practices reduce toll on wildlife - Anderson Nov-Dec p. 65

Swainson's hawk survival depend on land use - Anderson p. 67 (SB)

Unexpected side effects of chemicals acting as hormone mimics Fry p. 69 (SB)

In California ...'Agrobiodiversity' key to agricultural productivity - Qualset, McGuire, Warburton Nov-Dec p. 45

Inventory first step to conserving plant diversity - Pavlik

Nov-Dec p.18

Millions of generations old . . . Once lost, diversity of gene pools cannot be restored - Clegg Nov-Dec p. 34

Hot button issues for Endangered

Species Act reauthorization -

O'Brien Nov-Dec p. 35 (SB)

Private landowners critical to saving California biodiversity - Scott, Standiford, Pratini Nov-Dec p. 50

Nation's richest variety of insects in California - Ballmer p. 51 (SB)

Local conservation planning backed by UC expertise - Pratini p. 55 (SB)

Habitat fragmentation: The sum of the pieces is less than the whole - Scott, Pratini p. 56 (SB)

The case of Putah Creek ... Conflicting values complicate stream protection - Marchetti, Moyle Nov-Dec p. 73

The decline of sea-run fishes in California: An ongoing tragedy Marchetti, Moyle p. 74 (SB)

A truce in the water wars Marchetti, Moyle p. 77 (SB) 